\title{
FE SIMULATION OF SPACE STEEL FRAMES IN FIRE WITH WARPING EFFECT
}

\author{
Zhan-Fei Huang ${ }^{1, *}$ and Kang-Hai Tan ${ }^{2}$ \\ ${ }^{I}$ Research Fellow, School of Civil and Environmental Engineering, \\ College of Engineering, Nanyang Technological University, 50 Nanyang Avenue, Singapore 639798 \\ ${ }^{2}$ Assoc. Professor, School of Civil and Environmental Engineering, \\ College of Engineering, Nanyang Technological University, 50 Nanyang Avenue, Singapore 639798 \\ *(Corresponding author: E-mail: czfhuang@gmail.com)
}

Received: 8 January 2007; Revised: 19 March 2007; Accepted: 28 March 2007

\begin{abstract}
Most structural fire resistance analyses are confined to 2-D frames. To gain a more in-depth understanding of the response of a steel frame at elevated temperatures, 3-D simulations are necessary. This paper outlines the formulation of a two-noded 3-D beam-column to study the response of a steel frame in fire. The program is capable of small-strain large deformation analysis. Warping effect, a significant phenomenon in thin-walled members, is considered in the formulation. Degradation of steel mechanical properties at elevated temperatures is also considered, while thermal gradient is considered by slicing a cross-section into discrete segments. Creep can be either implicitly or explicitly taken into account. Several widely-used beam-to-column connections are approximated as zero-length semi-rigid springs. Their nonlinear moment-rotation relationships at elevated temperature are incorporated into the program. Unloading of both material stress-strain curve and moment-rotation characteristics of a connection are accounted for. The Newton-Raphson method is employed for nonlinear solving procedure. At the latter part of this paper, the program is verified against benchmark tests. All of them demonstrate the accuracy and reliability of the program.
\end{abstract}

Keywords: Finite element analysis, 3-D beam element, warping, fire, steel frame, creep

\section{INTRODUCTION}

In recent years, there is growing awareness in the understanding of the structural behaviour of a steel frame subjected to fire attack. This is partially owing to a series of tests conducted at Cardington, UK, which demonstrate the resilience of steel frames under fire conditions. Although a fairly extensive number of structural fire resistance experiments have been conducted, it was found these tests contained inherent limitations such as:

- $\quad$ Specimen boundary conditions are simplified as pined, roller or fully fixed, which are at variance with the much more complicated realistic boundary condition for a beam or column within an actual frame.

- Columns are tested as non-sway members in the test rig. In reality, even in a non-sway frame, columns may experience large sway during a compartment fire (Huang and Tan [1]).

- Interactions among structural components can hardly be simulated by experiments.

- Column post-buckling behaviour, slab membrane action as well as beam catenary actions cannot be captured by experiments.

- $\quad$ Fire resistance tests are extremely expensive.

Thus, researchers and engineers now resort more often to numerical analysis which is more versatile than purely analytical approaches such as Rankine method (Zeng et al. [2]; Huang and Tan $[3,4]$ ). Traditionally, 2-D finite element (FE) analyses have been carried to study the behaviour of steel frames in fire for decades. However, actual steel frames behave quite differently compared to 2-D simulation. For instance, steel columns are in reality subjected to biaxial bending and torque in addition to axial compression. Besides, warping effects is significant in thin-walled members. Therefore, in the past decade, more and more 3-D programs have been developed to achieve more accurate simulations (Wang et al. [5], Najjar and Burgess [6], Song et al. [7], Iu and Chan [9], Iu et al. [10], Ma and Liew [11]), the pace hastened by the rapid development of 
computer technology. These programs allow structural fire engineers to analyse a structure in a more holistic way through 3D full-frame analysis.

Iu and Ma's works differ to those of others in their plastic-hinge approach, which will be discussed herein.

In 2004, Iu and Chan extended Chan's program GMNAF to predict the behaviour of steel frames in fire. Both material and geometric nonlinearities were taken into account, while beam-to-column connections were simulated as semi-rigid springs. Material yielding is modelled by plastic hinges at both ends of an element. Limited by the nature of formulation, the actual yielding process of a beam was over-simplified although this formulation is famous for its high convergence rate due to simplicity in stiffness matrix formulation. The program was later used to investigate the behaviour of a steel frame during cooling stage which is essential for a full-history simulation of a frame in a real fire condition (Iu et al. [10]).

In Singapore, Ma and Liew [11] also developed a 3-D FE program for simulating steel frame in fire. Their approach was based on plastic hinge formulation, whereby the yielding of a steel cross-section is approximated by two nested 3-D stress-resultant surfaces by considering the softening effect of steel at elevated temperature. Such a model actually evolved from conventional single-surface plasticity model which is computationally efficient with compromise of prediction accuracy.

There are more works on traditional beam approach, where the plastification of a beam is monitored at discrete segments within a cross-section on integration points. In the UK, Najjar and Burgess [6] developed 3-D program 3DFIRE for unprotected steel frame simulation at elevated temperature. Warping effect is taken into account. The program was further refined by Bailey [8] with incorporation of functions such as semi-rigid spring, shear deformation as well as continuous floor slab of uniform temperature. Nevertheless, creep effect was not considered and degree of freedom (hereafter, DOF) to torsion was treated as scalar in the beam formulation.

This paper outlines the 3-D beam simulation work extended from on Bailey's work, so that creep strain is explicitly incorporated while torsion DOF is treated as a vector. A layered membrane reinforced concrete slab, which allows for uneven thermal distribution along the slab thickness direction, is being developed. Nonetheless, this to-be-incorporated slab will not be discussed herein. That is, this paper focuses on the formulation of the revised 3-D beam-column element.

\section{3-D STEEL BEAM FORMULATION}

The adopted 3-D steel beam element is extended from Bailey's work [8]. At each node of the beam, there are 8 DOFs in local coordinates which are transformed into 10 DOFs in global coordinates (Figure 1). In the formulations, it is assumed that:

- Only bi-symmetric sections (such as I-, rectangular and circular ones) are considered. As such, shear center coincides with the centroid of section.

- $\quad$ Element is straight and prismatic.

- Bernoulli-Euler hypothesis: a transverse plane remains plane and normal to the beam longitudinal axis.

- Shear strain is unconsidered, while strain unloading is taken into account.

- Cross-sectional area of a beam is undistorted under applied load and thermal effect. 
- Terms higher than 4th-order are neglected in the formulation. Under elevated temperature, steel frames may experience large deformation (Huang and Tan [1]), thus retaining high order terms is necessary for an accurate prediction.

- Warping effect is considered only for open thin-wall sections.

- Unlike translation and rotation, warping $\partial \theta_{z} / \partial z$ (Figure 1) is treated as a scalar.

- $\quad$ External loads are treated as conservative, i.e., they are independent of structural deformation.

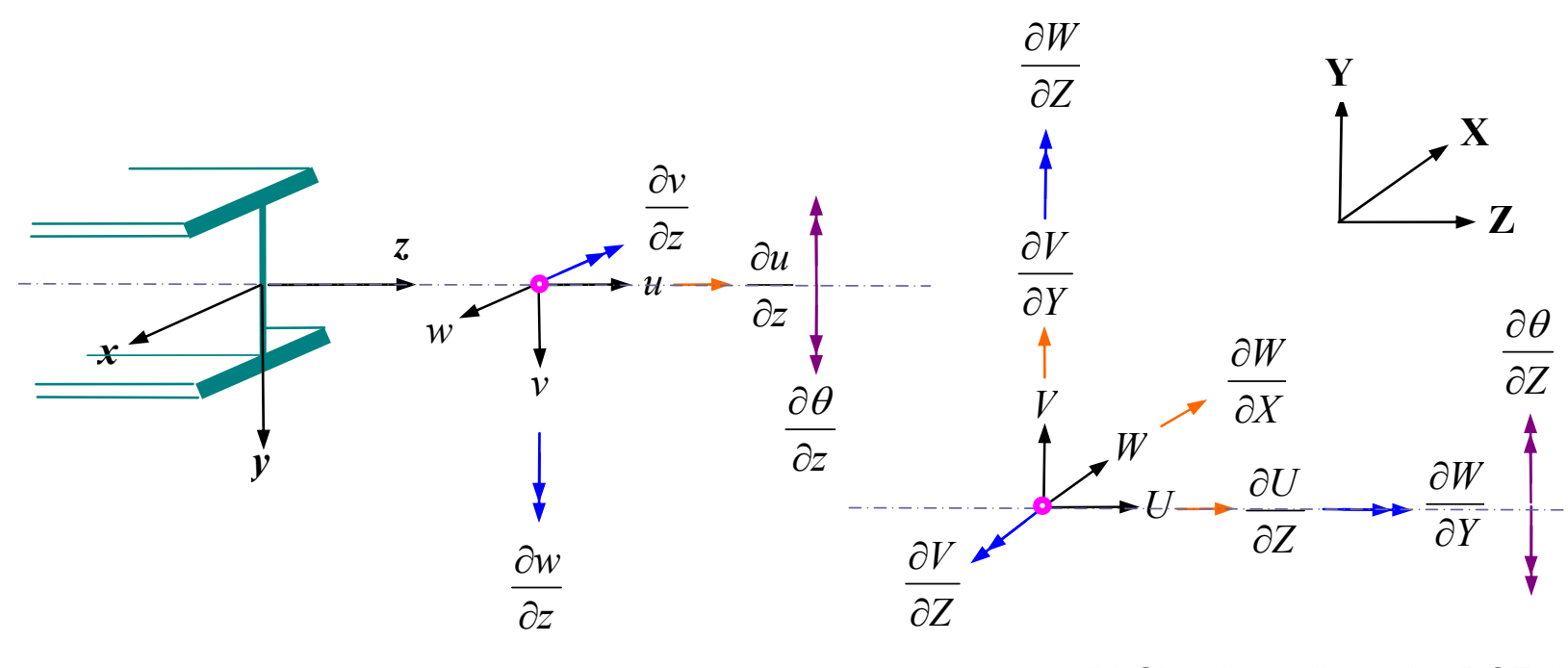

(a) Local coordinate (8 DOFs)

(b) Global coordinate (10 DOFs)

Figure 1. Definition of Degree of Freedoms at a Beam Node

The formulation of beam is based on Total Lagrangian description, which specifies the displacement of a point within a cross-section with regard to its initial position at the beginning of heating or loading. Under local coordinate system, $x$ - and $y$-axis are referred to the symmetric axes passing through the centroid of a cross section, while $z$-axis is the longitudinal axis of an element. Traditional cubic shape function $\langle N\rangle$ (Bathe [12]) is adopted to calculate the displacements at integration points along a beam as:

$u_{0}=\langle N\rangle\{\bar{u}\} \quad v_{0}=\langle N\rangle\{\bar{v}\} \quad w_{0}=\langle N\rangle\{\bar{w}\} \quad \theta_{z}=\langle N\rangle\left\{\overline{\theta_{z}^{\prime}}\right\}$

where

$$
\{\bar{u}\}=\left\{\begin{array}{c}
u_{i} \\
\left(\frac{\partial u}{\partial z}\right)_{i} \\
u_{j} \\
\left(\frac{\partial u}{\partial z}\right)_{j}
\end{array}\right\}^{\prime} \quad\{\bar{v}\}=\left\{\begin{array}{c}
v_{i} \\
\left(\frac{\partial v}{\partial z}\right)_{i} \\
v_{j} \\
\left(\frac{\partial v}{\partial z}\right)_{j}
\end{array}\right\} \quad\{\bar{w}\}=\left\{\begin{array}{c}
w_{i} \\
\left(\frac{\partial w}{\partial z}\right)_{i} \\
w_{j} \\
\left(\frac{\partial w}{\partial z}\right)_{j}
\end{array}\right\} \quad\left\{\overline{\theta_{z}}\right\}=\left\{\begin{array}{l}
\left(\theta_{z}\right)_{i} \\
\left(\theta_{z}^{\prime}\right)_{i} \\
\left(\theta_{z}\right)_{j} \\
\left(\theta_{z}^{\prime}\right)_{j}
\end{array}\right\}
$$

In Eq. (1), terms $u_{0}, v_{0}, w_{0}$ are translations in $z-, y$ - and $x$-axes, and $\theta_{z}$ is the twist angle along the beam axis. The subscript ' $\theta$ ' denotes at an integration point and ' $z$ ' is the longitudinal axis (i.e., $z$ - axis). In Eq. (2), vectors $\{\bar{u}\},\{\bar{v}\},\{\bar{w}\}$ and $\left\{\overline{\theta_{z}^{\prime}}\right\}$ denotes 16 DOFs at the respective nodes $i$ and $j$ of a beam as shown in Figure 1. 
A cross section is sliced into 64 segments to incorporate the temperature difference and the spreading of plasticity (Figure 2). Each segment has a central sampling point where its displacements are defined.

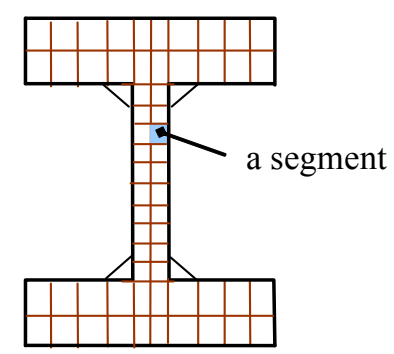

Figure 2. Segments of a Cross-section

Once the displacement at the centroid of a cross section is obtained, the associated 3 translations at any other point in this section can be calculated as (Figure 3):

$$
\begin{aligned}
& u=u_{0}-\left(y \cdot \sin \theta_{y}+x \cdot \sin \theta_{x}\right)+\omega \theta_{z}^{\prime} \\
& v=v_{0}-y+\left(y \cos \theta_{y} \cos \theta_{z}+x \cos \theta_{x} \sin \theta_{z}\right) \\
& w=w_{0}-x+\left(x \cos \theta_{x} \cos \theta_{z}-y \cos \theta_{y} \sin \theta_{z}\right)
\end{aligned}
$$
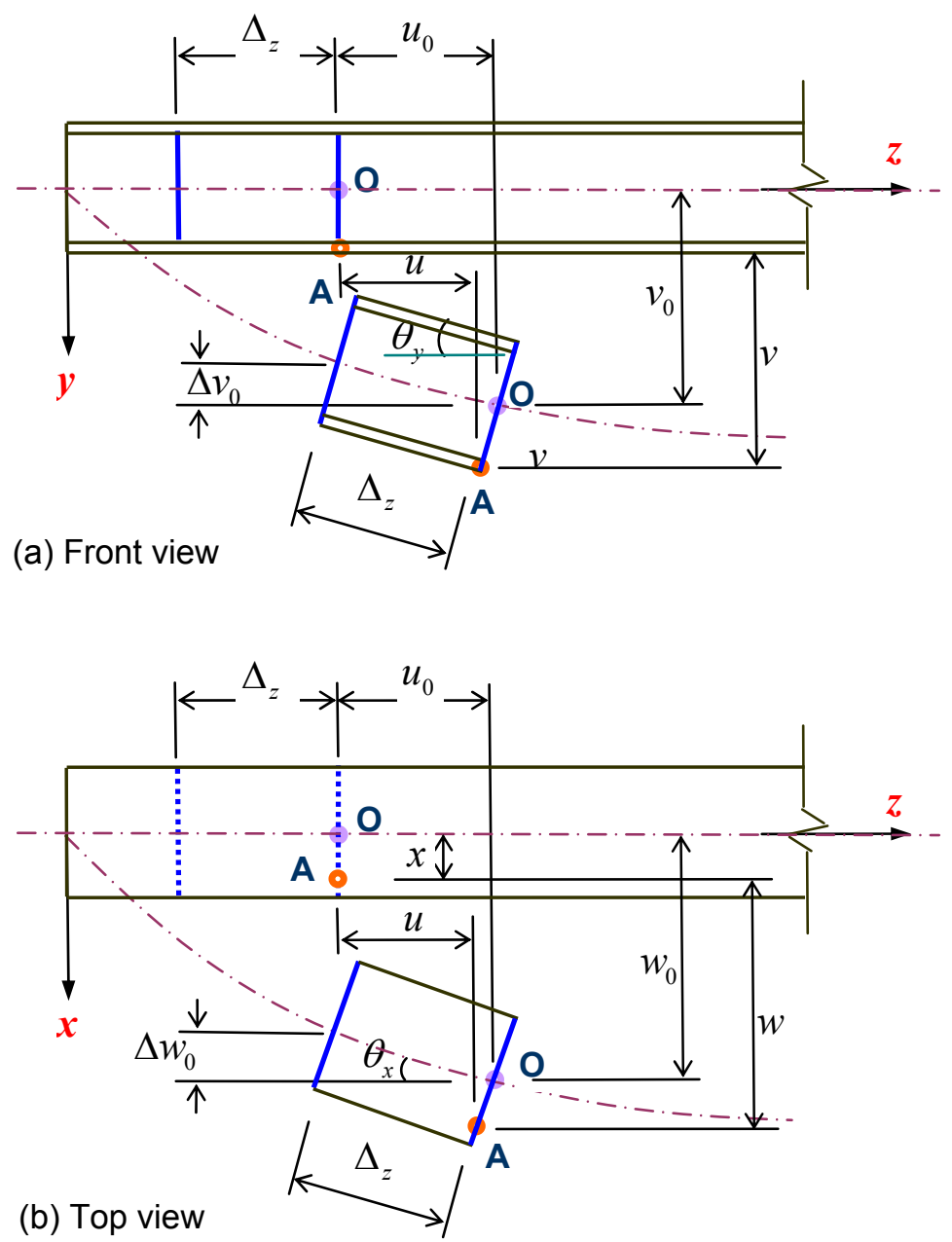


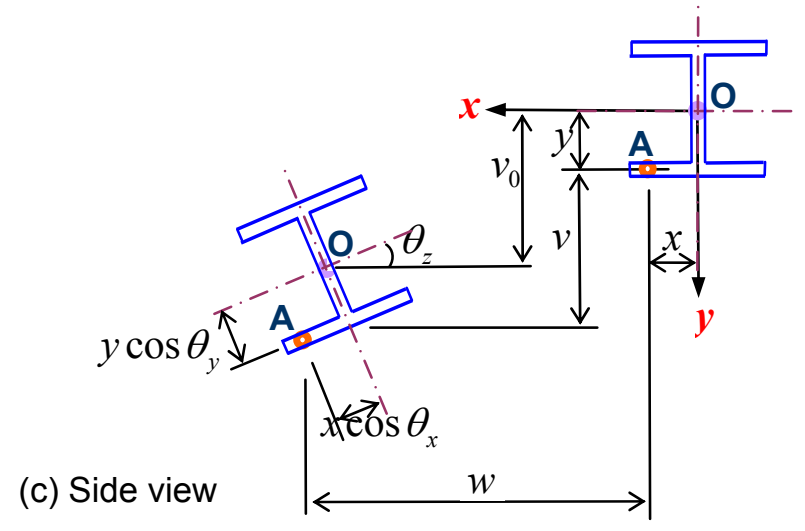

Figure 3. Definition of Space Displacements of a General Point within a Cross-section

in which $\omega$ is the normalized sectional coordinate for a particular point (Kohnke, [13]).

The associated slope of the deflected element in $y$-and $x$-axis can be respectively approximated as (Figure 3):

$v_{0}^{\prime}=\tan \theta_{y} \approx \sin \theta_{y}$

$w_{0}^{\prime}=\tan \theta_{x} \approx \sin \theta_{x}$

Further differentiating Eqs. (5) and (6) results in

$v_{0}^{\prime \prime}=\cos \theta_{y} \frac{d \theta_{y}}{d z}$

$w_{0}^{\prime \prime}=\cos \theta_{x} \frac{d \theta_{x}}{d z}$

Based on small rotation assumption, one obtains (Figure 3):

$$
\begin{aligned}
& \cos \theta_{y}=\sqrt{1-\left(v_{0}^{\prime}\right)^{2}} \\
& \cos \theta_{x}=\sqrt{1-\left(w_{0}^{\prime}\right)^{2}}
\end{aligned}
$$

Thus, Eqs. (8) and (9) can be rewritten as:

$$
\begin{aligned}
& \frac{d \theta_{y}}{d z}=\frac{v_{0}^{\prime \prime}}{\cos \theta_{y}}=\frac{v_{0}^{\prime \prime}}{\sqrt{1-\left(v_{0}^{\prime}\right)^{2}}} \\
& \frac{d \theta_{x}}{d z}=\frac{w_{0}^{\prime \prime}}{\cos \theta_{x}}=\frac{w_{0}^{\prime \prime}}{\sqrt{1-\left(w_{0}^{\prime}\right)^{2}}}
\end{aligned}
$$

Differentiating Eqs. (3) to (5) will produce:

$$
\begin{aligned}
& u^{\prime}=u_{0}^{\prime}-\left(y \cdot v_{0}^{\prime \prime}+x w_{0}^{\prime \prime}\right)+\omega \theta_{z}^{\prime \prime} \\
& v^{\prime}=v_{0}^{\prime}-y \frac{v_{0}^{\prime} v_{0}^{\prime \prime}}{\sqrt{1-\left(v_{0}^{\prime}\right)^{2}}}+x \theta_{z}^{\prime} \sqrt{1-\left(w_{0}^{\prime}\right)^{2}} \\
& w^{\prime}=w_{0}^{\prime}-x \frac{w_{0}^{\prime} w_{0}^{\prime \prime}}{\sqrt{1-\left(w_{0}^{\prime}\right)^{2}}}-y \theta_{z}^{\prime} \sqrt{1-\left(v_{0}^{\prime}\right)^{2}}
\end{aligned}
$$

By substituting Eqs. (14) to (15) into Green strain expression $\varepsilon_{z}=u^{\prime}+\frac{1}{2}\left[\left(u^{\prime}\right)^{2}+\left(v^{\prime}\right)^{2}+\left(w^{\prime}\right)^{2}\right]$, one has

$\varepsilon_{z}=u_{0}^{\prime}-y v_{0}^{\prime \prime}-x w_{0}^{\prime \prime}+\omega \theta_{z}^{\prime \prime}+\frac{1}{2}\left(u_{0}^{\prime}\right)^{2}-y u_{0}^{\prime} v_{0}^{\prime \prime}-x u_{0}^{\prime} w_{0}^{\prime \prime}+\omega u_{0}^{\prime} \theta_{z}^{\prime \prime}+\frac{1}{2} y^{2}\left(v_{0}^{\prime \prime}\right)^{2}+\frac{1}{2} x^{2}\left(w_{0}^{\prime \prime}\right)^{2}$ 


$$
\begin{aligned}
& +\frac{1}{2}\left(w_{0}^{\prime}\right)^{2}-x \frac{\left(w_{0}^{\prime}\right)^{2} w_{0}^{\prime \prime}}{\sqrt{1-\left(w_{0}^{\prime}\right)^{2}}}-y \theta_{z}^{\prime} w_{0}^{\prime} \sqrt{1-\left(v_{0}^{\prime}\right)^{2}}+\frac{1}{2} x^{2} \frac{\left(w_{0}^{\prime} w_{0}^{\prime \prime}\right)^{2}}{1-\left(w_{0}^{\prime}\right)^{2}}+\frac{1}{2} y^{2}\left(\theta_{z}^{\prime}\right)^{2}\left[1-\left(v_{0}^{\prime}\right)^{2}\right] \\
& +\frac{1}{2}\left(v_{0}^{\prime}\right)^{2}-y \frac{\left(v_{0}^{\prime}\right)^{2} v_{0}^{\prime \prime}}{\sqrt{1-\left(v_{0}^{\prime}\right)^{2}}}+x \theta_{z}^{\prime} v_{0}^{\prime} \sqrt{1-\left(w_{0}^{\prime}\right)^{2}}+\frac{1}{2} y^{2} \frac{\left(v_{0}^{\prime} v_{0}^{\prime \prime}\right)^{2}}{1-\left(v_{0}^{\prime}\right)^{2}}+\frac{1}{2} x^{2}\left(\theta_{z}^{\prime}\right)^{2}\left[1-\left(w_{0}^{\prime}\right)^{2}\right]
\end{aligned}
$$

Warping of an I-section is considered with reference to ANSYS (Kohnke, [13]).

Once the axial strains are obtained, the Principle of Virtual Work can be applied:

$\delta W=\int_{V} \sigma_{z} \delta \varepsilon_{z} d V-\langle Q\rangle\{\delta q\}=0$

in which $\sigma_{z}$ denotes axial stress, $\langle Q\rangle$ external load vector, $V$ total volume of an element and $\{\delta q\}$ incremental displacements.

Following the standard nonlinear FE procedure, the incremental equilibrium equations are formulated at the global structural level:

$\left[\mathbf{K}_{\mathbf{T}}\right] \cdot\{\Delta \mathbf{q}\}=\{\Delta \mathbf{Q}\}$

where $\left[\mathbf{K}_{\mathbf{T}}\right]$ denotes global tangent stiffness matrix, $\{\Delta \mathbf{q}\}$ global incremental displacements and $\{\boldsymbol{\Delta} \mathbf{Q}\}$ out-of-balance forces. Traditional Newton-Raphson method is used to solve Eq. (19). To improve the convergence rate and to ensure a monotonic convergence, potential-energy-based line search method is employed in conjunction with N-R method.

Steel material modelling, which takes unloading into account, is in line with Tan et al. [18].

As mentioned, our formulation differs from Bailey's [8] algorithm at three points.

(1) Firstly, the nodal torsion parameter $\theta_{z}$ is treated as a vector and thus it can be decomposed into three global rotations $\partial W / \partial Y, \partial W / \partial Z$ and $\partial V / \partial Z$ after coordinate transformation (Figure 1). Bailey treated $\theta_{z}$ as a scalar which is an independent DOF. Obviously, the new approach is more rational and one less DOF is needed under global coordinate system.

(2) Secondly, creep strain is incorporated explicitly into the program. Although creep strain is implicitly considered by some widely-used stress-strain models like EC3 Pt.1.2 [14] when heating rate falls into the range of 2 to $50^{\circ} \mathrm{C} / \mathrm{min}$, theoretically, creep strain should be treated explicitly due to its transient nature. Numerous studies have shown the importance of incorporating creep strain explicitly into numerical simulation (Harmathy [15], Cheng [17], Furumura and Shimohara [16], Tan et al. [18], Zeng et al. [2], Huang et al. [19]).

Generally, when the temperature increases beyond 450 to $500^{\circ} \mathrm{C}$, which commonly take place under a real fire, steel creep strain becomes significant. This study adopts Harmathy's creep model [20], which is based on a concept put forward by Dorn [21] in which the effect of variable temperature is considered. Dorn [21] proposed a temperature-compensated time $\theta$ which is expressed as:

$\theta=\int e^{-\frac{Q}{R T^{\prime}}} d t$

where $Q$ is the activation energy of creep $(\mathrm{J} / \mathrm{mol}), R$ is the gas constant $(\mathrm{J} / \mathrm{mol} \cdot \mathrm{K})$, and $T^{\prime}$ is the absolute temperature. 
Harmathy [20] derived an analytical expression of creep strain rate $\dot{\varepsilon}_{c r}$ for ASTM A36 structural steel:

$$
\begin{aligned}
& \dot{\varepsilon}_{c r}=Z \exp \left(\frac{-Q}{R T^{\prime}}\right) \operatorname{coth}^{2}\left[\frac{3 t Z \exp \left(\frac{-Q}{R T^{\prime}}\right)}{\varepsilon_{c r, 0}}\right]^{1 / 3} \text { (time hardening) } \\
& \dot{\varepsilon}_{c r}=Z \exp \left(\frac{-Q}{R T^{\prime}}\right) \operatorname{coth}^{2}\left[\frac{\varepsilon_{c r}^{*}}{\varepsilon_{c r, 0}}\right] \quad \text { (strain hardening) }
\end{aligned}
$$

in which $Z=0.026 S^{4.7}$, when $S \leq 15,000$ (psi),

$Z=1.23 \times 10^{16} \exp (0.0003 S)$, when $15,000<S \leq 45,000 \quad$ (psi);

where $\mathrm{S}$ is the second Kirchhoff stress;

$\varepsilon_{c r, 0}=1.7 \times 10^{-10} S^{1.75}$;

$\frac{Q}{R}=70,000^{\circ}$ Rankine;

$T^{\prime}=$ degrees Fahrenheit +459.67 (Rankine);

$t=$ time $(\mathrm{hr})$

$\varepsilon_{c r}^{*}=\sum\left|\dot{\varepsilon}_{c r}\right| \cdot \Delta t$, compounded creep strain (Harmathy [15]).

Both strain-hardening rule and time-hardening rule are incorporated into FEMFAN3D. Predictor and corrector technique is applied in calculating the creep strain $\varepsilon_{c r}$ at a faster convergence rate (Levy [22]).

(3) Thirdly, the approach differs from Bailey's [8] in that we do not adopt subdivision technique on each member. In Bailey's [8] formulation, each member was subdivided into three elements with the central one being 80 percent of member length. This was to cater for a better reflection of spread of material yielding in the proximity at nodal area. However, this purpose was achieved with greater CPU time. In our approach, Newton-Cotes scheme is employed and there are two integration points on element boundary (Bathe [12]).

In addition, elastic unloading of stress-strain relationship is also considered in line with Tan et al. [18]. To model the beam-to-column connections, a two-noded zero length semi-rigid spring element is employed. Under local coordinate system, this spring element has two DOFs, namely, rotations about $x$ and $y$ axes (Figure 1). The other six nodal DOFs on a beam end are assumed to be rigidly connected to the others. At the present time, there is very little experimental data for joint characteristics at elevated temperatures although data for the in-plane rotational characteristics of steel beam-to-column connection at ambient temperature abound. Thus, only El-Ramawi's model [23] using Ramberg-Osgood expression to establish the relationship between the connection bending moment $M_{c o n}^{T}$ and its relative rotation $\theta_{c o n}^{T}$ is incorporated into the program. Unloading of $M_{c o n}^{T}-\theta_{c o n}^{T}$ curve is modelled in line with El-Rimawi et al [24]'s work. 


\section{NUMERICAL VERIFICATION}

The program has been validated against a fairly number of benchmark tests numerically and experimentally. Following shows the most representative ones.

\subsection{Deflection of a Flat Arch Subject to a Lateral Loading at Ambient Temperature}

This benchmark test is used to validate the large deformation analytical capability of program FEMFAN3D. A flat arch that supports a monotonically increasing point load at its mid-span (Figure 4a, from ABAQUS [25] is chosen for this purpose. Creep is not included in the simulation. Due to symmetry, only half of the arch is modelled, with a rigid vertical roller at 'A'. A vertical load of $N / 2$ is applied at 'A'. The arch is pin-connected at the end ' $\mathrm{B}$ ' (Figure 4a) and it consists of a rectangular section with 1 inch width and 2 inch height. The arch is divided into 20 linear elements for a better simulation of flat arch. Displacement control is adopted to trace the snap-through phenomenon of flat arch. Figure $4 \mathrm{~b}$ illustrates clearly that the vertical deflection $v$ predicted from FEMFAN3D compares very well with ABAQUS results [25]. The large-displacement capability of FEMFAN3D is verified.

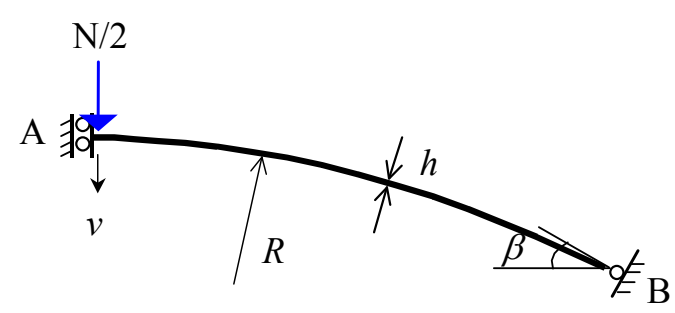

(a)

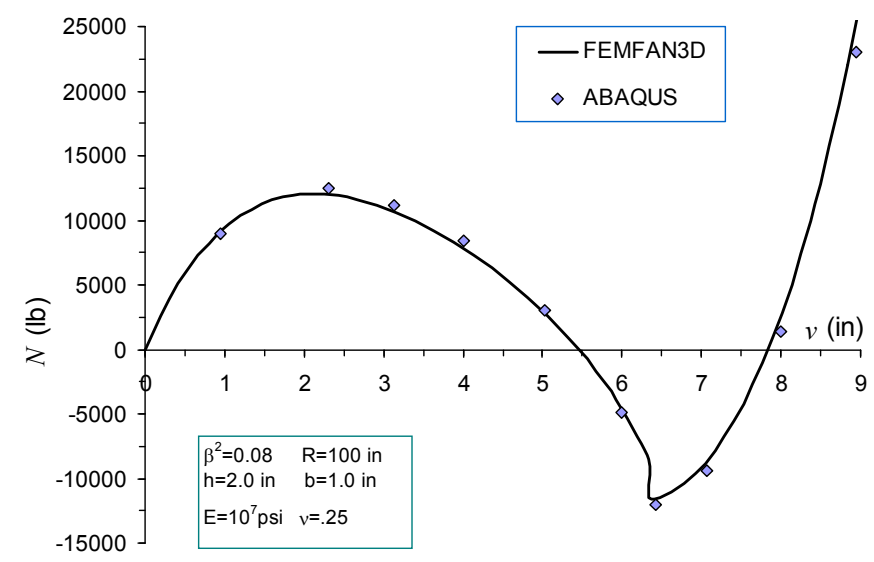

(b)

Figure 4. (a) Loading and Dimension of Flat-arch with Pinned Ends, (b) Mid-span Deflection

\subsection{Deflection of a Subframe under Fire Condition with Creep Considered}

This benchmark test is used to validate the creep effect on the structural behaviour of a steel frame under fire conditions.

Furumura and Shimohara [16] developed a F.E. elastic-plastic creep analysis for 2D steel frames in fire. Based on the same example, Najjar [26] validated his program 3DFIRE using Furumura and Shimohara's work. There is no publication on the simulation by using Bailey's formulation. It should be mentioned that in Najjar's original beam formulation, upon which Bailey's work extended, shear strain and strain unloading were not taken into account.

Some of assumptions adopted by Furumura and Shimohara are listed below:

(1) The thermal strain of steel $\varepsilon_{t h}$ is calculated as:

$\varepsilon_{\text {th }}=5.04 \times 10^{-9} T^{2}+1.13 \times 10^{-5} T$

where $T$ is in ${ }^{\circ} \mathrm{C}$. 
(2) The stress-strain relationship of SM50 steel is shown in Figure 5. where $E_{0}^{T} / E_{0}^{20}=-8.75 \times 10^{-7} T^{2}-3.87 \times 10^{-4} T+1.008$

In this equation, $E_{0}^{T}$ and $E_{0}^{20}$ are the elastic modulus at temperature $T$ and $20^{\circ} \mathrm{C}$, respectively. The material descriptions also include the behaviour during unloading, in tension or, temperature variation. Kinematic hardening rule is applied as unloading occurs.

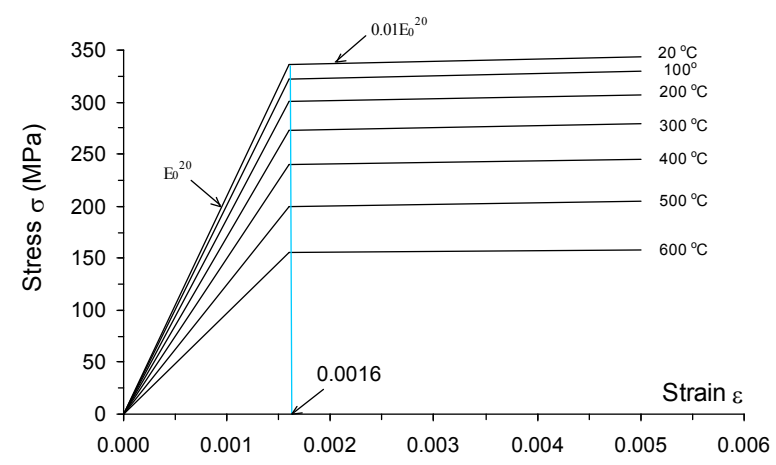

Figure 5. Stress-strain Relationship of Steel SM50 at Elevated Temperature (Furumura and Shimohara [16])

(3) To evaluate the creep deformation, it is assumed that the creep strain increment $\dot{\varepsilon}_{c r}$ for SM50 steel during the time increment $d t$, is related to time $t$, absolute temperature $\mathrm{T}$, and current stress $\sigma$ in the following form:

$$
\dot{\varepsilon}_{c r}=10^{\left(c-\frac{a}{2.3} \cdot \frac{1}{T}\right) \frac{1}{n}} \cdot\left(\frac{2.37 \times|\sigma|}{3.4}\right)^{\left(\frac{b}{2.3} \cdot \frac{1}{T}+\alpha\right) \frac{1}{n}} \cdot n^{\frac{n-1}{n}} \cdot\left(\int_{0}^{\varepsilon_{c}}\left|\frac{d \varepsilon_{c r}}{d t}\right| d t\right)^{\frac{n-1}{n}} \cdot d t \cdot \operatorname{sgn} \sigma
$$

where $\mathrm{c}=20.53, \alpha=-7.25, \mathrm{n}=0.35, \mathrm{a}=4.5 \times 10^{4}, \mathrm{~b}=1.9 \times 10^{4}, T:$ absolute temperature, $t:$ time (min.), $\sigma:$ stress $\left(\mathrm{kg} / \mathrm{mm}^{2}\right), \varepsilon_{c r}$ : creep strain (\%).

Strain-hardening rule is applied for the calculation of the non-stationary creep deformation.

(4) The concrete slabs do not interact with the steel frame system or contribute to its stiffness.

(5) The stress and strain states of the element are uniaxial and are evaluated only at both ends of the element. The stress state within the element is interpolated by using the values at both ends of each element.

(6) The deformations of members by axial force and bending moment are considered, but the shearing and local deformations are ignored.

A total of three beam-columns have been analysed by Furumura and Shimohara [16], with different end conditions. Limited by the paper length, only sub-frame $2 \mathrm{a}$ is presented here. Figure 6a shows the geometry and loading of the frame, which is a simplified structural model suggested by Furumura and Shimohara [16] to represent a multi-storey frame. The concentrated loads at the column top represent loadings transferred from top storeys. The developments of cross-sectional temperatures profile is shown in Figure 6b, where significant thermal gradient is presented throughout the heating.

In this paper, the numerical results from Furumura and Shimohara, Najjar and us are compared. All works adopt Furumura and Shimohara's material model, except that Najjar's did not take creep into account limited by the nature of his program 3DFIRE. To illustrate creep effect, the 
prediction of FEMFAN3D excluding creep effect is also shown. In our simulation, the beam is divided into ten elements of even length, while each column is divided into four elements.

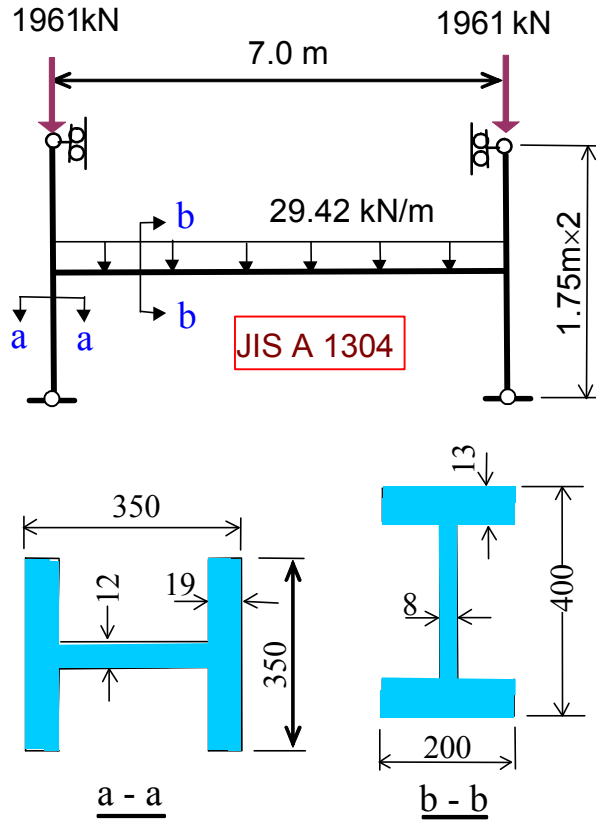

(a) Dimension and Loading

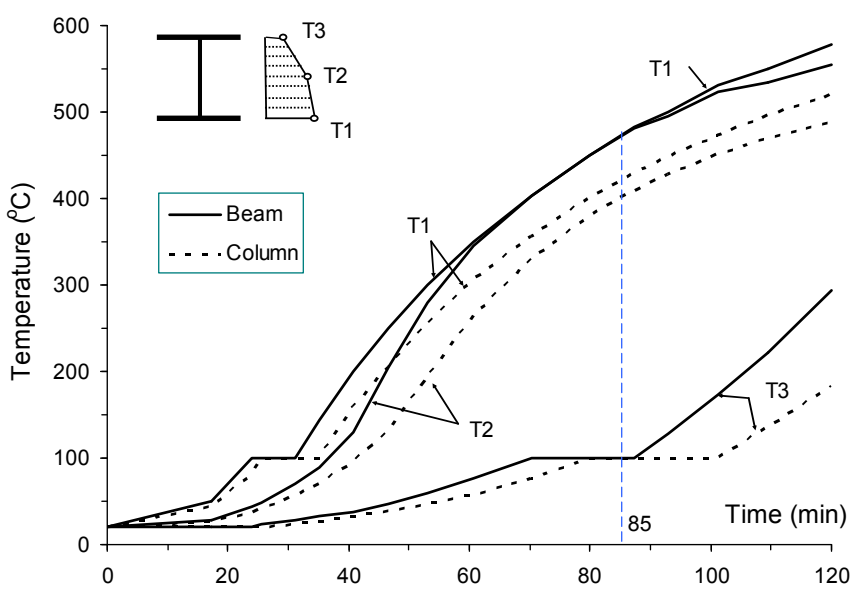

(b) Temperature Development within Members

Figure 6. Subframe-2a Subjected to Fire Standard JIS A 1304 Fire

Figure 7 compares the results predicted by all parties. Figure $7 \mathrm{a}$ shows the development of horizontal displacement at beam end $u$, as well as mid-span deflection $v_{\text {mid }}$, whereas Figure $7 \mathrm{~b}$ shows the progress of beam internal axial force $P$. In general, (1) current analysis with creep effect yields good agreement with Furumura and Shimohara's prediction within the full heating history albeit some discrepancies exist; (2) since creep effect was excluded from Najjar's simulation, his result somewhat contains discrepancy towards the end of heating when creep becomes significant.

These deformations and internal force should be analysed in detail.

In terms of mid-span deflection $v_{\text {mid }}$ (Figure 7a), both Furumura et al. and FEMFAN3D analyses give nearly the same result throughout the heating, while 3DFIRE agrees well with the other two only before $85 \mathrm{~min}$. Beyond 85 minutes, due to the negligence of creep strain, 3DFIRE predicts much smaller $v_{\text {mid }}$ compared to the others. At 85 minutes, the corresponding temperatures at the bottom flange and web of steel sections ( $T 1$ and $T 2$ in Figure $6 \mathrm{~b}$ ) attain about $450^{\circ} \mathrm{C}$ and $400^{\circ} \mathrm{C}$, respectively. It is acknowledged that creep starts to affect the behaviour of a steel structure beyond around $450^{\circ} \mathrm{C}$. At the end of heating, that is at $t=120 \mathrm{~min}$. while $T 1=580^{\circ} \mathrm{C}$ and $T 2=505^{\circ} \mathrm{C}$ in the beam, the magnitude of $v_{\text {mid }}$ predicted by FEMFAN3D (or Furumura and Shimohara) is almost twice that of 3DFIRE. By the same reasoning, FEMFAN3D prediction without creep effect differs much from that with creep effect beyond $85 \mathrm{~min}$.

With respect to beam end horizontal movement $u$, all predictions follow closely with each other before $85 \mathrm{~min}$. The predictions differ from each other beyond $85 \mathrm{~min}$ when the temperature rises above $450^{\circ} \mathrm{C}$ and creep effect becomes significant. 
It is also interesting to check the progress of beam internal axial force $P$ under the rising temperature. Figure $7 \mathrm{~b}$ shows that difference among three analyses starts after 40 minutes of heating. Both 3DFIRE and FEMFAN3D predict slightly higher $P$ than Furumura and Shimohara. It is reasonable that the 3DFIRE analysis overestimated $P$ which is induced by the thermal expansion of beam — the absence of creep effect stiffens the adjoining columns. Besides, FEMFAN3D prediction is still slightly greater than Najjar's beyond 40 minutes, when $P$ begins to decrease due to rapid development of beam lateral deflection. This is mainly due to the fact that elastic unloading of $\sigma-\varepsilon$ model which is considered in this approach, was not considered by Najjar who adopted tangent modulus unloading scheme. A decrease of $P$ engenders unloading at the top fibers of heated beam. The significant effect of unloading in the numerical simulation has been discussed by Franssen [27].

Beyond 85 minutes, the presence of significant creep strain leads to a faster decreasing $P$ by both Furumura et al. and FEMFAN3D than that of Najjar's result.

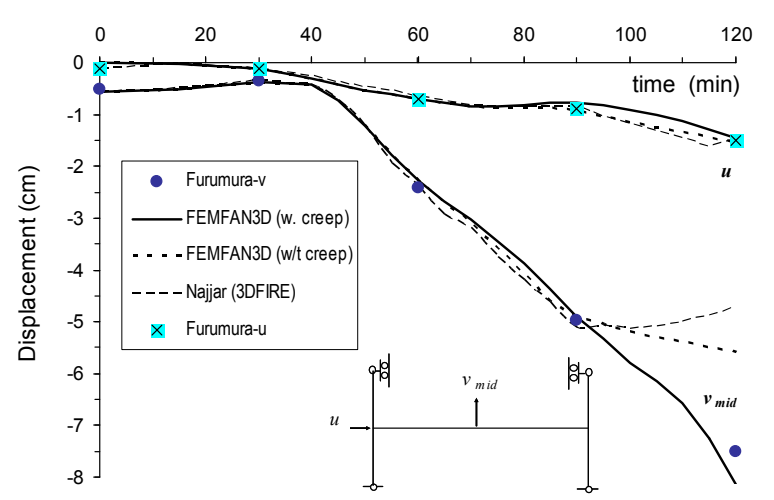

(a) displacement

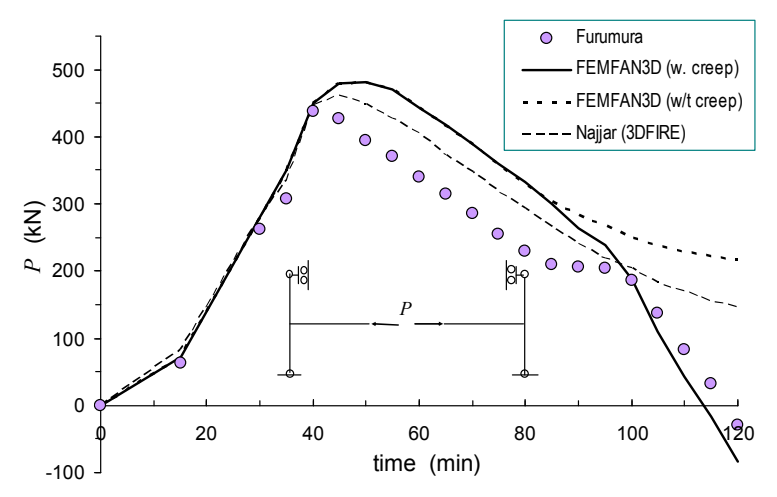

(b) beam internal axial force

Figure 7. Comparison of Predictions on Frame Deformation and Internal Force

\subsection{A 2-Storey Space Frame at Ambient Temperature}

This comparison is carried out to verify the 3D analysis capability. In 1971, Morino and Lu reported two second-order elastic-plastic analyses of two space frames, which are also analysed by program FEMFAN3D. Limited by the paper length, only the comparison on the 2-storey one is presented here. The frame is subjected to monotonically increasing load at room temperature until it fails. Creep is not included in the simulation. Figure 8 shows the frame geometry and the load-deflection curves at node ' 5 ' of the frame. All members are of $14 \mathrm{~W} 43$ I-section and with slenderness ratio $l / r_{W}=60$, in which $r_{W}$ denotes radius of gyration about the weak axis. Numbers on the Morino and Lu's curve show the sequence of plastic hinge formations in the frame.

Clearly, the predictions agree well with Morino and Lu's results up to the point when the cross-section of the first predicted plastic hinge starts to yield. Beyond that point, the prediction of external load $N$ is slightly greater than theirs corresponding to the same horizontal movement $U$. This is mainly due to the different approaches adopted. The approach considers the spread of plasticity across a member under increasing $N$, while Morino and Lu assumes fully elastic behaviour of a section before it becomes fully plastic. In their analysis, once a plastic hinge forms, a mechanical hinge will be inserted on the element and the analysis continues until the whole frame turns into a mechanism. 


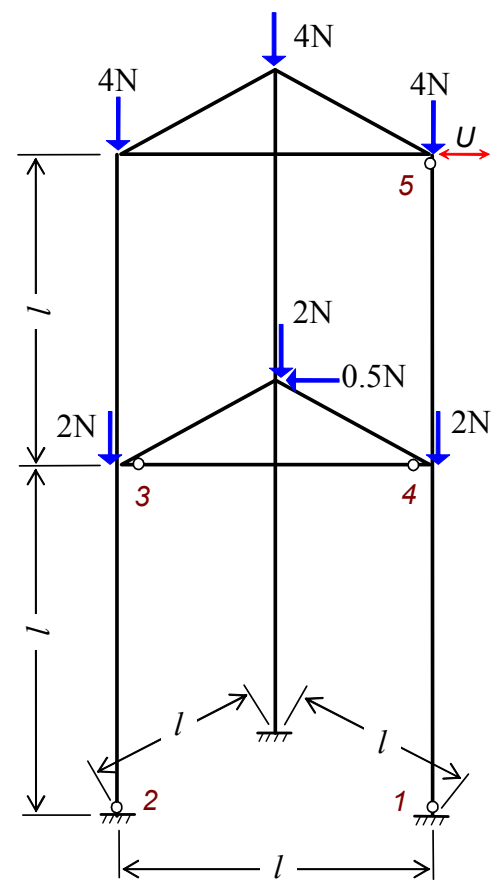

(a) Dimension and Loading

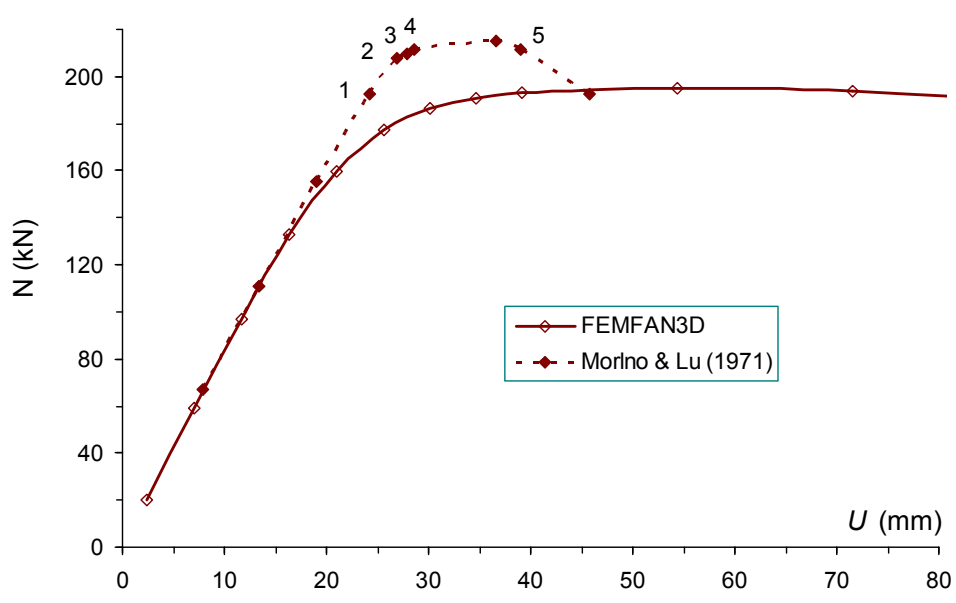

(b) Horizontal Movement at Point-5

Figure 8. Collapse Process of a Two-storey Space Frame (Morino and Lu [28])

\subsection{Response of Semi-rigid Connected Beams in Fire}

Bailey [8] studied the influence of semi-rigid connections on a pin-roller steel beam subjected to fire as shown in Figure 9a. The beam is of $305 \times 165$ UB40 section and grade 43 steel. Three constant concentrated loads act at the quarter points of beam, corresponding to a load ratio of 0.6 (according to BSI [29]). Different end restraints are considered, viz. 25\%, 50\%, 75\% and 100\% scaling of both the stiffness and strength of the extended end-plate characteristics as proposed by El-Ramawi et al. [30]. Temperature is uniformly distributed along the beam length as well as across the section. The connection temperature takes $70 \%$ of the beam temperature. Since the Ramberg-Osgood stress-strain model (BSI [29]) adopted by Bailey is not incorporated in program FEMFAN3D, in this analysis, EC3 model (CEC [14]) is used. Thus, explicit creep is not included in the FEA.
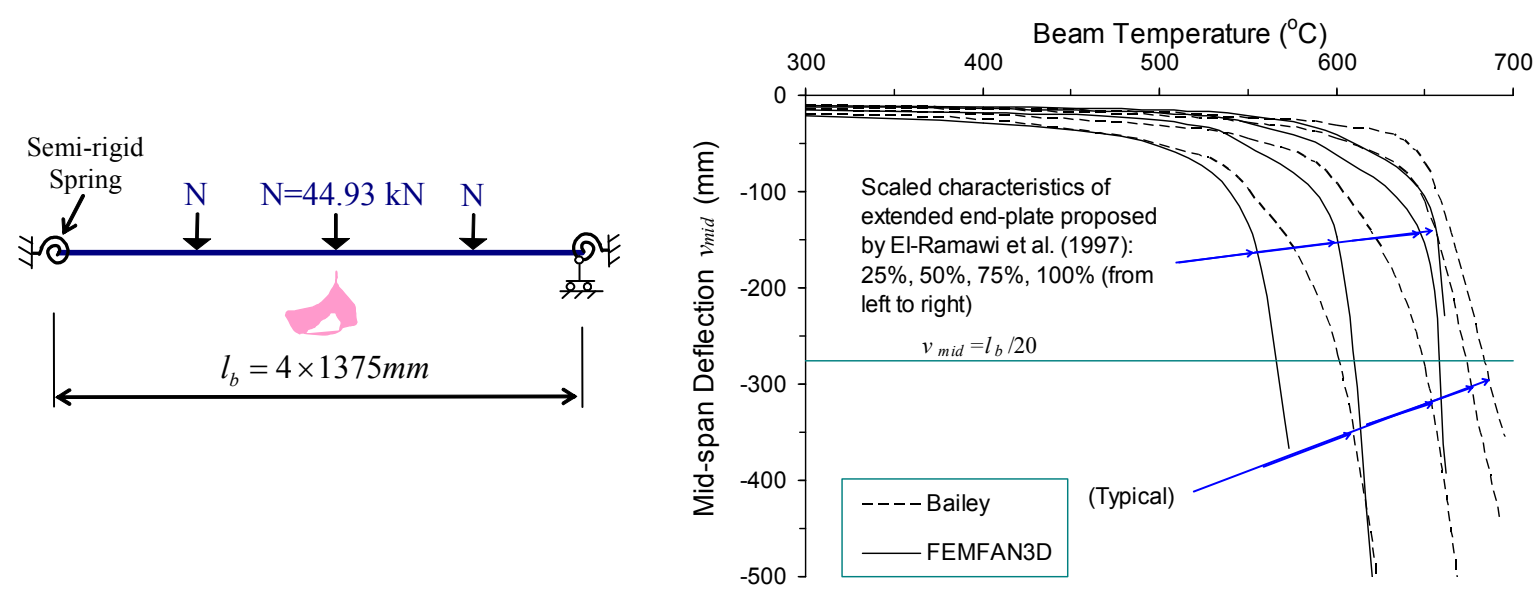

Figure 9. Collapse Process of a Heated Steel Beam with Semi-rigid Connection (Bailey [8]) 
The mid-span deflection $v_{\text {mid }}$ predicted by FEMFAN3D and Bailey is presented in Figure $9 \mathrm{~b}$. Adopting $v_{\text {mid }}=l_{b} / 20$ as the beam critical state, Figure $9 \mathrm{~b}$ illustrates that the critical temperature is increased significantly by incorporating the semi-rigid connections. There is very little difference between the predictions pertaining to $75 \%$ and $100 \%$ connection rigidities. Nonetheless, Figure 9b demonstrates that for the entire four cases, FEMFAN3D predicts smaller critical temperatures than Bailey's results. This is because beyond $500^{\circ} \mathrm{C}$, with the plastic zone spreading from the mid-span towards the two ends, EC3 model with no strain-hardening assumes infinitesimal value for tangent modulus $E_{T}^{T}$ beyond the yield strength, while Ramberg-Osgood model with strain hardening gives much greater values for $E_{T}^{T}$.

\subsection{Experimental Validation}

Finally, the program is validated against a plane fire frame test reported by Franssen et al. [31] under fire conditions as few experimental results are available for the behaviour of a space skeletal steel frame in fire. This portal frame consists of two $203 \times 203$ UC52 columns and one $406 \times 178$ UB54 beam, all of which are made of grade $43 \mathrm{~A}$ steel. No test was carried out to measure the actual mechanical properties of steel. Thus, in the first FE analysis, steel yield strength at ambient temperature $f_{y}^{20}$ is first assumed to be $275 \mathrm{MPa}$. The frame was analysed using the temperature profiles measured at different parts of the frame.

The development of mid-span defection of the beam $v_{\text {mid }}$ is shown in Figure 10. Obviously, the FE analysis slightly overestimates $v_{\text {mid }}$ and this is due to: (1) $f_{y}^{20}$ might be underestimated, and (2) strain-hardening is not considered by EC3 Pt.1.2 stress-strain model. Simply increasing $f_{y}^{20}$ to $305 \mathrm{MPa}$ will yield a relatively accurate prediction compared to test result (Figure 10).

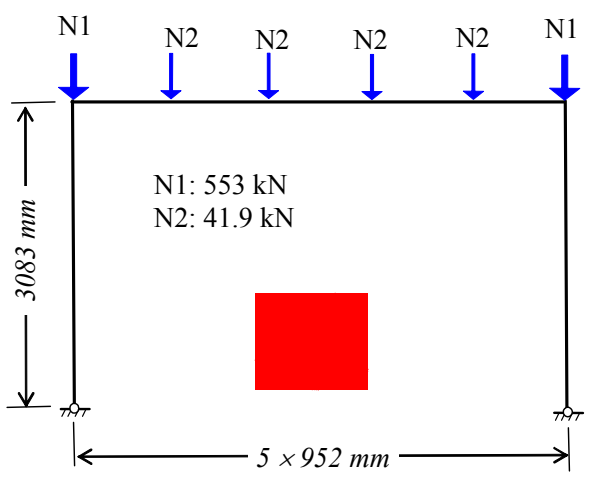

(a) Dimension and Loading

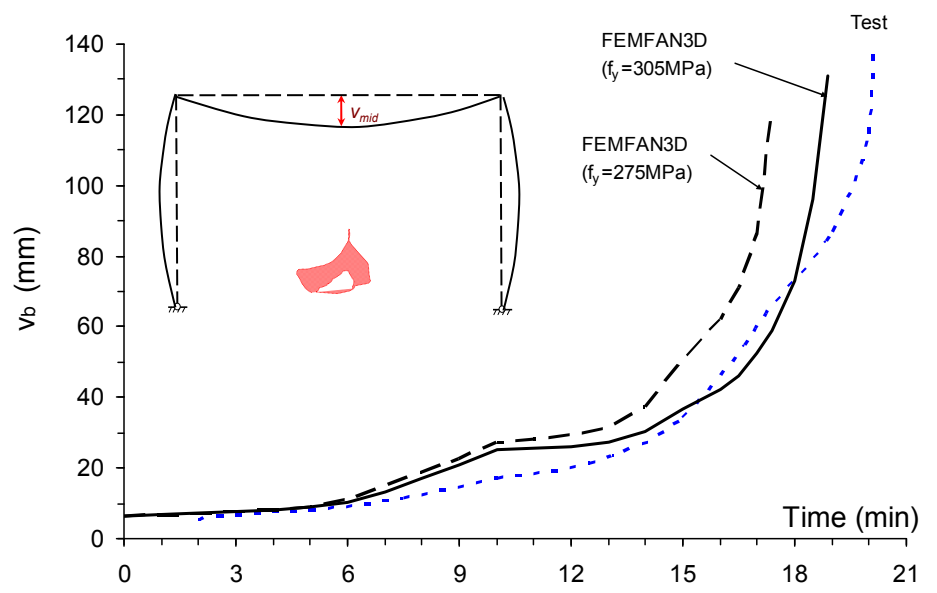

(b) Beam Mid-span Deflection

Figure 10. Collapse Process a Portal Frame in an Actual Fire (Franssen [31])

\section{CONCLUSIONS}

This paper outlines the formulations of a 3D small-strain large-deformation beam-column element being used to simulate the structural response of a skeletal steel frame under fire conditions. The cross-section of a beam-column is divided into segments to simulate the uneven temperature distribution under fire conditions. Creep strain can be included explicitly. Beam-to-column 
connections are simulated as semi-rigid springs in the formulation. Five benchmark tests are carried out to verify different aspects of the program, viz., large deformation, creep, effect of semi-rigid connection on the deflection of a heated beam, full collapse process of a space frame at room temperature, and deformation of a plane frame under elevated temperature. In general, good agreement is obtained between numerical predictions and the published results. Unfortunately, validation for space skeletal steel frames in fire was not performed due to the lack of test data. Apart from demonstrating the capability and reliability of the FE program, these verifications also illustrate that response of a structural member in fire is substantially influenced by the interactions among adjoining members.

Development of RC and composite slab element, which is requisite for more accurate simulation of an actual structure, is currently being carried out.

\section{ACKNOWLEDGEMENTS}

The authors would like to thank Nanyang Technological University for the research grant RGM 28/03 as well as Ministry of Education grant ARC 5/03, without which the conduct of this research will not be possible.

\section{REFERENCES}

[1] Huang, Z.F. and Tan, K.H., "Fire Resistance of Compartments within a High-rise Steel Frames: New Sub-frame and Isolated Member Models", J Construct. Steel Res., 2006, Vol. 62, No. 10, pp. 974-986.

[2] Zeng, J.L., Tan, K.H. and Huang, Z.F., "Primary Creep Buckling of Steel Columns in Fire", J. Constuct. Steel Res., 2003, Vol. 59, No. 8, pp. 951-970.

[3] Huang, Z.F. and Tan, K.H., "Analytical Fire Resistance of Axially Restrained Steel Columns", J. Struct. Engng. ASCE, 2003a, Vol. 129, No. 11, pp. 1531-1537.

[4] Huang, Z.F. and Tan, K.H., "Rankine Approach for Fire Resistance of Axially-and-flexurally Restrained Steel Columns", J. Construct. Steel Res., 2003b, Vol. 59, No. 12, pp. 1553-1571.

[5] Wang, Y.C., Lennon, T. and Moore, D.B., "The Behaviour of Steel Frames Subjected to Fire", J. Construct. Steel Res., 1995, Vol. 35, pp. 291-322.

[6] Najjar, S.R. and Burgess, I.W., "A Nonlinear Analysis for Three-dimensional Steel Frames in Fire Conditions", Engng Struct., 1996, Vol. 18, No. 1, pp. 77-89.

[7] Song, L., Izzuddin, B.A., Elnashai, A.S. and Dowling, P.J., "An Integrated Adaptive Environment for Fire and Explosion Analysis of Steel Frames - Part I: Analytical Models", J. Construct. Steel Res., 2000, Vol. 53, pp. 63-85.

[8] Bailey, C.G., "Development of Computer Software to Simulate the Structural Behaviour of Steel-framed Buildings in Fire", Comput \& Struct., 1998, Vol. 67, pp. 421-438.

[9] Iu, C.K. and Chan, S.L., "A Simulation-based Large Deflection and Inelastic Analysis of Steel Frames Under Fire”, J. Construct. Steel Res., 2004, Vol. 60, pp. 1495-1524.

[10] Iu, C.K., Chan, S.L. and Xiao, X.Z., "Nonlinear Pre-fire and Post-fire Analysis of Steel Frames", Engng Struct., 2005, Vol. 27, pp. 1689-1702.

[11] Ma, K.Y. and Liew, J.Y.R., "Nonlinear Plastic Hinge Analysis of Three-dimensional Steel Frames in Fire”, J. Struct. Engng., ASCE, 2004, Vol. 130, No. 7, pp. 981-990.

[12] Bathe, K.J., "Finite Element Procedures", Prentice Hall, Inc., 1996.

[13] Kohnke, P., “ANSYS User's Manual for Revision 5.0, Vol. IV, Theory”, Swanson Analysis Systems, Inc., Houston, USA, 1992. 
[14] Commission of European Communities(CEC), "Design of Steel Structures: Part 1.2: General Rules - Structural Fire Design (EC3 Pt.1.2”, Eurocode 3, Brussels, Belgium, 1995.

[15] Harmathy, T.Z., "Creep Deflection of Metal Beams in Transient Heating Processes, with Particular Reference to Fire”, Can. J. Civ. Eng., 1976, Vol. 3, No. 2, pp. 219-228.

[16] Furumura, F. and Shimohara, Y., "Inelastic Behavior of Protected Steel Beams and Frames in Fire", Report of the Research Laboratory of Engineering Materials, 1978, No.3, pp. 1-14, Tokyo Institute of Technology, Japan.

[17] Cheng, W.C., "Theory and Application on the Behaviour of Steel Structures at Elevated Temperatures", Comput \& Struct., 1983, Vol. 16, No. 1-4, pp. 27-35.

[18] Tan, K.H., Ting, S.K. and Huang, Z.F., "Visco-Elasto-Plastic Analysis of Steel Frames in Fire”, J. Struct. Engng, ASCE, 2002, Vol. 128, No. 1, pp. 105-114.

[19] Huang, Z.F, Tan, K.H. and Ting, S.K., "Heating Rate and Boundary Restraint Effects on Fire Resistance of Steel Columns with Creep", Engng Struct., 2006, Vol. 28, No. 6, pp. 805-817.

[20] Harmathy, T.Z., “A Comprehensive Creep Model”, J. Basic Engng Trans., ASME, 1967, Vol. 89, pp. 469-502.

[21] Dorn, J.E., "Some Fundamental Experiments on High Temperature Creep", J. Mech. \& Phys Solids, 1954, Vol. 3, pp. 85-116.

[22] Levy, A., "High-Temperature Inelastic Analysis", Comput \& Struct., 1984, Vol. 13, pp. 249-256.

[23] El-Rimawi, J.A., Burgess, I.W. and Plank, R.J., "The Influence of Connection Stiffness on the Behaviour of Steel Beams in Fire", J. Construct. Steel Res., 1997, Vol. 43, No. 1-3, pp. $1-15$.

[24] El-Rimawi, J.A., Burgess, I.W. and Plank, R.J., "The Treatment of Strain Reversal in Structural Members During the Cooling Phase of a Fire", J. Construct. Steel Res., 1996, Vol. 37, No. 2, pp. 115-135.

[25] ABAQUS, "Standard Verification Manual, Version 5.5", Hibbitt, Karlsson \& Sorensen, Inc., 1995.

[26] Najjar, S.R., Three-Dimensional Analysis of Steel Frames and Subframes in Fire, Ph.D. thesis, Sheffield University, U.K, 1994.

[27] Franssen, J.M., "The Unloading of Building Materials Submitted to Fire”, Fire Saf. J., 1990, Vol. 16, pp. 213-227.

[28] Morino, S. and Lu, L.W., “Analysis of Space Frames”, Fritz Engineering Laboratory, Report No. 331.13., 1971.

[29] BSI, "Code of Practice for Fire Resistant Design: Structural Use of steelwork in Building, Part 8, BS5950”, London, UK, 1990.

[30] EI-Rimawi, J.A., Burgess, I.W. and Plank, R.J., "The Influence of Connection Stiffness on the Behaviour of Steel Beams in Fire", J. Construct. Steel Res., 1997, Vol. 43, No. 1-3, pp. $1-15$.

[31] Franssen, J.M., Cooke, G.M.E. and Latham, D.J., "Numerical Simulation of a Full Scale Fire Test on a Loaded Steel Framework", J. Construct. Steel Res., 1995, Vol. 35, pp. $377-408$. 


\section{Nomenclature}

\begin{tabular}{|c|c|}
\hline$A=$ & Area $\left(\mathrm{m}^{2}\right)$ \\
\hline$E_{0}=$ & Elastic modulus at ambient temperature (MPa); \\
\hline$E_{0}{ }^{T}=$ & Elastic modulus at elevated temperature $T$ \\
\hline$E_{T}^{T}=$ & Tangent modulus at elevated temperature $T$; \\
\hline$f_{y}^{20}=$ & Yield strength at ambient temperature (MPa); \\
\hline$f_{y}^{T}=$ & Yield strength at elevated temperature $T(\mathrm{MPa})$; \\
\hline $\mathbf{K}_{\mathbf{T}}=$ & Frame global tangent stiffness matrix; \\
\hline$l=$ & Length of a beam/column (m); \\
\hline$N=$ & External load $(\mathrm{N})$ \\
\hline$P=$ & Applied axial load $(\mathrm{N})$ \\
\hline$r_{S}=$ & radius of gyration about strong axis; \\
\hline$R=$ & Gas Constant $(\mathrm{J} / \mathrm{mol} \cdot \mathrm{K})$ or, utilization factor (CEC 1995); \\
\hline$S=$ & Second Kirchhoff stress; \\
\hline$t=$ & Time; \\
\hline$T=$ & Temperature $\left({ }^{\circ} \mathrm{C}\right)$ \\
\hline$T^{\prime}=$ & Absolute temperature (Rankine); \\
\hline$u_{0}, v_{0}, w_{0}=$ & Translations at centroid of a cross-section; \\
\hline$u, v, w=$ & Translations at a specific point within a cross-section; \\
\hline$v_{\text {mid }}=$ & Mid-span deflection on a beam (m); \\
\hline$\theta=$ & Temperature compensated time (hr); \\
\hline$\varepsilon_{c r}{ }^{*}=$ & Compounded creep strain (Harmathy, 1976); \\
\hline$\dot{\varepsilon}_{c r}=$ & Creep strain rate; \\
\hline$\varepsilon_{y}{ }^{T}=$ & Yielding strain at elevated temperature $T$; \\
\hline$\lambda=$ & Slenderness ratio; \\
\hline$\Delta \mathbf{Q}=$ & Vector of out-of-balance forces $(\mathrm{kN})$ \\
\hline$\Delta \mathbf{q}=$ & Vector of increments displacements (m); \\
\hline Subscript & \\
\hline 0 & At centroid of a section; \\
\hline$z$ & Longitudinal coordinate. \\
\hline
\end{tabular}

